\title{
Updated CPT-based p-y formulation for laterally loaded piles in cohesionless soil under static loading
}

\author{
S.K. Suryasentana ${ }^{1}$ BEng \\ B.M. Lehane ${ }^{2}$ BE, MAI, DIC, PhD, FIEAust, CPEng
}

${ }^{1} \mathrm{PhD}$ Student

Oxford University, Dept. of Engineering Science

(Formerly the University of Western Australia)

${ }^{2}$ Corresponding Author

Professor, School of Civil \& Resource Engineering

The University of Western Australia.

35 Stirling Highway, Crawley WA 6009, Australia

Phone +61 864882417

Fax +61864881044

E-mail: Barry.Lehane@uwa.edu.au 


\begin{abstract}
The $p-y$ method is currently the most popular design method to predict the response of piles to lateral load. The authors had previously used numerical methods to develop a CPT-based $p-y$ formulation for piles in sand and this has subsequently been shown by independent verification to show considerable promise. This paper addresses some of the uncertainties associated with the original $p-y$ formulation by examining the influence of pile bending stiffness, the presence of a water table, the cross-sectional shape of the pile and soil non-homogeneities. Numerical experiments are presented examining these four effects and lead to an updated proposal for a CPT-based $p-y$ formulation. This formulation, which is consistent with the original proposal, is validated against 3D Finite Element calculations and data obtained from a full scale offshore monopile foundation supporting a wind turbine.
\end{abstract}




\section{Introduction}

The $p-y$ method is the de facto standard for the analysis of laterally loaded piles due to its simplicity and long, proven record in Industry. This method uses $p-y$ curves to represent the non-linear relationship between the net soil resistance at any depth per unit length of soil adjacent to a pile $(p)$ and the lateral deflection of the pile at that depth $(y)$.

There are a number of formulations to derive these $p-y$ curves but all use some measure of soil strength to determine the relationship between $p$ and $y$. Currently, the most popular formulation to derive these $p-y$ curves is that recommended by the American Petroleum Institute (API) and (Det Norske Veritas) DNV design standards (API 2011; DNV 2013); this formulation is referred to, in the following, as the API method. The API method for piles in sand is derived empirically using data from full-scale tests on free-headed piles and it uses the soil friction angle, $\phi^{\prime}$, as the primary measure of soil strength to determine the relationship between $p$ and $y$.

Although the API method has been used in Industry with reasonable success, it has a number of acknowledged limitations and uncertainties. Firstly, the API method was derived based on the test results from small diameter piles and its applicability to large diameter piles is uncertain. Doubts about the applicability of the API method to large diameter piles have been expressed previously (Murchison \& O’Neill 1983) but the increasing popularity of large diameter monopiles as the foundation of choice for onshore and offshore wind turbines has intensified interest in the method's reliability. Secondly, the API method is highly sensitive to the choice of the sand friction angle $\phi^{\prime}$ and such sensitivity is exacerbated by the need to employ empirical correlations with in-situ test results to assess $\phi^{\prime}$. 
To address these limitations, some researchers (Novello 1999, Dyson \& Randolph 2001 and Suryasentana \& Lehane 2014a) proposed using the cone penetration test (CPT) end resistance $\left(\mathrm{q}_{\mathrm{c}}\right)$ as the measure of soil strength to determine the relationship between $p$ and $y$. The primary advantage of this approach is that it is a direct method and not susceptible to the subjectivity associated with inference of $\phi^{\prime}$ values.

The $p-y$ formulation proposed by Suryasentana \& Lehane (2014a), which was derived for a wished-in-place circular pile in dry sand, was obtained via a regression analysis on a large series of 3D Finite Element (FE) computations that predicted the lateral pile response in a variety of different sands and a cavity expansion approximation using Finite Elements to predict corresponding CPT $\mathrm{q}_{\mathrm{c}}$ profiles in each sand deposit. The sand was modelled in Plaxis $2 \mathrm{D}$ and $3 \mathrm{D}$ analyses using a non-linear elasto-plastic constitutive model, referred to as the Hardening Soil (HS) model (Schanz et. al. 1999). The regression analysis led to the following equation, which was based on results obtained for a large range of soil parameters typical of loose to dense sands for pile diameters ranging from $0.5 \mathrm{~m}$ to $5 \mathrm{~m}$ and for normalised lateral deflection values $(\mathrm{y} / \mathrm{D})$ in the range 0.01 and 0.2 .

$p_{u}=2.4 \gamma z D\left(\frac{q_{c}}{\gamma z}\right)^{0.67}\left(\frac{z}{D}\right)^{0.75}$

$p=p_{u}\left(1-\exp \left(-6.2\left(\frac{z}{D}\right)^{-1.2}\left(\frac{y}{D}\right)^{0.89}\right)\right)$

Where $p_{\mathrm{u}}$ is the ultimate lateral resistance (per unit length), $\gamma$ is the soil unit weight, $z$ is the depth below ground level, $D$ is the pile diameter and $q_{c}$ is the CPT end resistance.

Equation (1) has subsequently been assessed against several published cases studies by Suryasentana \& Lehane (2014b) and Li et al. (2014) and shown to provide consistently good 
predictions. Equation (1) was, however, derived for flexible circular piles under fully dry and homogeneous soil conditions. Therefore, its applicability to rigid or non-circular piles under fully saturated or non-homogeneous conditions is uncertain. This paper does not deal with the dynamic response of piles to lateral loading; this subject is discussed by Dobry et al. (1982) and many others.

\section{a) Influence of pile bending stiffness on p-y curves}

Although the $p-y$ relationship is understood to be a soil-pile interaction response, rather than solely a soil response, all existing $p-y$ formulations are independent of the pile's flexural rigidity $\left(E_{p} I_{p}\right)$. Previous investigations on the dependency of the $p-y$ response on $E_{p} I_{p}$ have been conflicting. Ashour \& Norris (2000), for example, investigated the effect of $E_{p} I_{p}$ on $p-y$ curves using the Strain Wedge analysis technique and deduced that the stiffness and ultimate resistance of the $p-y$ response generally increased with $E_{p} I_{p}$. In contrast, Fan \& Long (2005) used 3D Finite Element (3D FE) analyses and deduced that the $p-y$ response is generally independent of $E_{p} I_{p}$. The type of response of a laterally loaded pile depends primarily on the soil stiffness, pile length (L) and $E_{p} I_{p}$ value. Poulos \& Hull (1989) postulated that, under lateral loading, a pile essentially rotates as a rigid body if $L$ is less than $1.48 R$ or behaves flexibly (i.e. bending is significant) if $L$ exceeds $4.44 R$, where $R=\left(E_{p} I_{p} / E_{s}\right)^{0.25}$ and $E_{s}$ is an equivalent linear Youngs modulus for the soil. A rigid response results in a shearing force at the pile toe, which can be a significant portion of the total lateral soil resistance for a large diameter pile. Moreover, the rotational behaviour may induce a different $p-y$ response to that of a flexing behaviour. Therefore, given that Equation (1) was derived for statically loaded flexible piles, its suitability for the design of rigid piles is examined in the following. 


\section{b) Influence of the presence of a water table on p-y curves}

The API method relates $p$ to the vertical effective stress $\left(\sigma_{v}^{\prime}\right)$ and hence assumes implicitly that the $p-y$ response at any given depth in unsaturated soil is stiffer and reaches a higher ultimate resistance than that in saturated soil. Although Equation (1) was derived for fully dry conditions, Suryasentana \& Lehane (2014b) substituted the $\gamma z$ term with the vertical effective stress $\left(\sigma_{v}^{\prime}\right)$ in this equation and obtained reasonable predictions for fully saturated conditions. A specific examination of the suitability of this substitution is made in this paper.

\section{c) Influence of pile cross-sectional shape on p-y curves}

Equation (1) was derived for a pile with a circular cross-sectional shape and hence the applicability of the equation to non-circular cross-sections is uncertain. Murchison and O'Neill (1983) proposed applying a shape factor to their $p-y$ formulation of 1.5 for uniformly tapered piles or $\mathrm{H}$ piles but suggested that a square pile of width, $B$, would generate the same lateral soil response as a circular pile with a diameter of $B$. However, Ashour \& Norris (2000) and Reese \& Van Impe (2001) argue that a square pile mobilizes a higher net lateral soil resistance than a circular pile with the same width. Additionally, Gleser (1984) contended that a square pile mobilizes less lateral soil resistance than a circular pile with the same second moment of area; this contention implies that a square pile of width $B$ mobilizes less lateral soil resistance than a circular pile of diameter 1.14B. Based on the foregoing, it would appear that there is consensus that a square pile of width $B$ can mobilize the same or more lateral soil resistance than a circular pile of diameter $B$ but not more than a circular pile of diameter 1.14B. Given the widespread use of square precast concrete piles, modifications required to Equation (1) to allow predictions of the lateral response of such piles are investigated in the following. 


\section{d) Effect of soil non-homogeneity on p-y curves}

It is recognised that $p-y$ springs do not directly allow for the transfer of shearing forces between soil layers. The development of Equation (1) indirectly allows for such transfer as the pressure and displacement values calculated at any given soil layer incorporate interaction with adjacent soil layers. Equation (1) was, however, derived assuming a homogeneous sand layer for which the stiffness at a given strain level varied only with the stress level. The applicability of Equation (1) to lateral pile analysis in situations where there are appreciable differences in soil properties is investigated in this paper.

\section{Analysis and results}

The suitability of Equation (1) to cater for issues (a) - (d) is investigated here by comparing the $p-y$ curves obtained from a variety of 3D Finite Elements simulations of lateral pile tests. As was the case for the derivation of Equation (1) in Suryasentana \& Lehane (2014a), the Plaxis 2D program was used to derive $\mathrm{CPT} q_{c}$ profiles from cavity expansion analyses and the Plaxis 3D FE program was used to simulate lateral pile tests (with the load applied at ground level) under a free head condition; the Hardening Soil $(H S)$ constitutive model and fully drained conditions were assumed throughout. The mesh set-up details, mesh calibration, CPT $q_{c}$ derivation and $p-y$ curves extraction process are described in Suryasentana \& Lehane (2014a). A loose and a dense sand with the $H S$ parameters provided in Table 2 were employed to represent a typical range of sands encountered in-situ. The HS parameters are described in Suryasentana \& Lehane (2014a) and Schanz et. al. (1999).

\section{a) Influence of pile bending stiffness on p-y curves}

To evaluate the dependency of the $p-y$ response on $E_{p} I_{p}$ and to investigate if the response for rigid piles is different from that of flexible piles, lateral pile test FE simulations were carried out using four different sets of pile properties, as shown in Table 1. The first three of these 
employed $E_{p} I_{p}$ values of $1.0,0.1$ and 10 times that of a solid concrete pile. The $E_{p} I_{p}$ value adopted for the fourth analysis assumed a solid steel pile with a length 4 times less than that of the other 3 piles; this pile is classified as rigid according to the Poulos \& Hull (1989) criterion. The FE simulations were carried out for the loose and dense sands (with properties given in Table 2) under fully unsaturated conditions with two different pile diameters $(2 \mathrm{~m}$ and $0.5 \mathrm{~m})$, whilst maintaining similar L/D ratios.

For clarity purposes, only the results of the $2 \mathrm{~m}$ diameter piles are presented in the figures (although the results of the $0.5 \mathrm{~m}$ diameter piles provide closely comparable trends). Figure 1 shows the effect of different $E_{p} I_{p}$ values on the $p-y$ curves in the loose and dense sand at $z / D=1$ and 2. It is evident that the $p-y$ response is independent of $E_{p} I_{p}$ for both the flexible and rigid piles in the loose and dense sand. This finding supports that of Fan \& Long (2005) that $p-y$ curves are not a function of the flexural rigidity.

\section{b) Influence of the presence of a water table on $p$-y curves}

Lateral pile test FE simulations were carried out using $2 \mathrm{~m}$ and $0.5 \mathrm{~m}$ diameter flexible piles (Case F1 as shown in Table 1) for two typical cases involving a water table at (i) $\mathrm{z} / \mathrm{D}=1.5$, which is typical of many onshore sites and (ii) ground level, which is representative of offshore environments. The FE simulations were carried out for the loose and dense sand (with properties given in Table 2).

The net pressures calculated at $\mathrm{z} / \mathrm{D}=1$ and $\mathrm{z} / \mathrm{D}=2$ for the $2 \mathrm{~m}$ diameter pile are normalised by the vertical effective stress, $p /\left(\sigma^{\prime}{ }_{v} D\right)$, and plotted against normalised displacement $(y / D)$ in Figure 2. It is seen that, when plotted in this normalised form, the curves tend to reach the same ultimate value for each depth. The $p-y$ curves at depths below the water table are, however, a little stiffer than their fully unsaturated counterparts and mobilize their normalized ultimate 
resistances at a lower displacement. Further analysis indicated that $p-y$ curves above and below the water table could be unified approximately by factoring the normalised displacement $(y / D)$ by the following function of the vertical total and effective stresses at any given depth:

$$
\eta_{w}=\left(\frac{\sigma_{v}-u_{g}}{\sigma_{v}^{\prime}}\right)^{0.5}
$$

where $u_{g}$ is the water pressure at ground level $(z=0)$. The modification of the $y / \mathrm{D}$ values according to equation (1) for the analyses summarised in Figure 2 is shown on Figure 3 and is seen to provide a relatively unique normalised pressure-displacement response at each depth. The maximum effect of this factor arises for full saturated conditions and leads to an initial stiffness about 35\% stiffer than that predicted by Equation (1).

\section{(c) Square vs. circular piles}

The lateral pile test FE simulations summarised in Table 3 were carried out to examine differences between fully rough piles with square and circular cross-sectional areas. Three different widths were selected for the square piles: the first was set equal to the diameter of the circular pile $(B=D)$, the second had a width that gave the same second moment of area as the circular pile $(\mathrm{B}=\mathrm{D} / 1.14)$ and the width of the third was so that its perimeter was the same as the circular pile $(\mathrm{B}=\mathrm{D} / 1.27)$. The $\mathrm{E}_{\mathrm{p}}$ value for each pile was assigned such that $E_{p} I_{p}$ was identical for all piles. The FE simulations were carried out in fully unsaturated loose and dense sand (with the properties given in Table 2).

The calculated normalised pressure-displacement curves at $z / D=1$ for the $0.5 \mathrm{~m}$ diameter pile are plotted on Figure 4. It is evident that the normalised $p-y$ curves for the square piles with widths of $\mathrm{B}=\mathrm{D}$ and $\mathrm{B}=\mathrm{D} / 1.14$ are generally stiffer than that of the circular pile. The best match in response between a circular and square pile emerged when the square pile had approximately 
the same perimeter as the circular pile. Further evidence supporting this observation is provided in Figure 5, which shows that the pile head load-displacement behaviour of a circular pile and a square pile of equivalent perimeter are virtually identical for a number of pile diameters; which indicates that this trend is not diameter specific. Square piles per unit volume of concrete are therefore about $27 \%$ more efficient than circular piles in resisting lateral load (if structural moment capacities are not controlling).

\section{(d) Effect of soil non-homogeneity on p-y curves}

The effects of non-homogeneity were examined in lateral pile test FE simulations involving $2 \mathrm{~m}$ and $0.5 \mathrm{~m}$ diameter flexible piles (F1 as shown in Table 1) installed in an unsaturated, layered stratigraphy comprising an upper layer with a thickness of $1.5 \mathrm{D}$ overlying a deep uniform layer. The first set of analyses was performed with the upper layer having the properties of dense sand and the lower comprising loose sand (with the properties given in Table 2). The second set of analyses examined the pile response with the loose sand overlying the dense sand.

The calculated results for the $2 \mathrm{~m}$ diameter pile are plotted on Figure 6 . It is evident that the $p$ $y$ responses at $\mathrm{z} / \mathrm{D}=1$ and $\mathrm{z} / \mathrm{D}=2$ are not dependent on the nature of the sand at a distance of 1

D above or below these two depths. These analyses therefore support the general validity of the use of $p-y$ springs (and Equation 1) for laterally loaded pile analysis. $p$ - $y$ curves were also extracted for the transition depth at $3 \mathrm{~m}$ below ground level. These curves indicate that the response at this depth is not equal to the average values for a loose or dense sand but is weighted towards the p-y response of the underlying soil. 


\section{Updated Formulation}

\section{Rationale for updating}

The analyses described above suggest that Equation (1) can be updated with the inclusion of two factors, $\eta_{\mathrm{w}}$ and $\mathrm{D}_{\mathrm{e}}$ :

$p=p_{u}\left(1-\exp \left(-6.2\left(\frac{z}{D_{e}}\right)^{-1.2}\left(\frac{\eta_{w} y}{D_{e}}\right)^{0.89}\right)\right)$

where $p_{u}$ is given in equation $1 \mathrm{a}$, the saturation factor $\left(\eta_{\mathrm{w}}\right)$ is given in equation (2) and the effective diameter, $D_{e}$ is the actual diameter, $D$, of a circular pile and $1.27 \mathrm{~B}$ for a square pile of width B. Equation (3) is identical to Equation (1) for circular piles in dry sand conditions.

Equation (1a) indicates that the ultimate lateral resistance $\left(p_{u}\right)$ continues to increase both with $z / D$ and $y / D$. The numerical analyses only examined $p-y$ curves at $z / D \leq 4$ as the sand properties in upper 4 diameters of a laterally loaded pile dominate its performance and very often the pile's finite moment capacity restricts the development of high lateral stresses at deeper levels. The calculations indicated that, at these deeper levels, the ultimate net lateral pressure value does not exceed the CPT $\mathrm{q}_{\mathrm{c}}$ value; this limit is considered a sensible upperbound for lateral resistance at depth.

The initial stiffness of the $p-y$ curve, which is found by differentiating Equation (3) with respect to $y$, tends to an infinite value as $y$ approaches zero. It can be shown that that this differentiation can only yield a finite value at $y=0$ when the exponent of $y$ is unity (noting that differential is zero if this exponent is greater than 1). The regression analysis of the FE computations was 
therefore repeated by increasing the exponent of 0.89 to a fixed value of unity. This analysis gave the updated $p-y$ formulation provided in Equation (5).

The initial stiffness, $d \mathrm{p} / d \mathrm{y}$ at $y=0$, determined using Equation (5), gives a much lower value than the true initial stiffness $\left(k_{0}\right)$. This occurs as the FE analyses were not conducted using a constitutive model that incorporated the high stiffness of sand at very small (elastic) strain levels (note that the regression of the $\mathrm{FE}$ analyses was performed for $0.01 \leq \mathrm{y} / \mathrm{D} \leq 0.1$ ). If required, $k_{0}$ can be assessed directly from in-situ measurements of small strain shear moduli $\left(\mathrm{G}_{\max }\right)$ and using the following approximation based on recent analyses given in Di Laora \& Rovithis (2014):

$k_{0}=\left(\frac{d p}{d y}\right)_{y=0} \approx 4 G_{\max }\left(1+v_{0}\right) \approx 4.5 G_{\max }$

where $v_{0}$ is the small strain Poissons ratio (typically 0.1 to 0.2 ). The now common use of the seismic cone allows measurement of $G_{\max }$ as well as $q_{c}$. Fully elastic conditions in sand can be assumed when the elemental strain is less than about 0.003\% (Tatsuoka et al., 1997). Using this strain limit and the approximate transformation based on cavity expansion proposed by Jardine (1992), the y/D value at which conditions in the sand mass become essentially nonelastic is about $0 \cdot 01 \%$.

The updated CPT-based formulation may therefore be written as:

$p=4.5 G_{\max } y$

$y / D_{e}<0.0001$

$p=p_{u}\left(1-\exp \left(-8.9\left(\frac{y}{D_{e}}\right)\left(\frac{\sigma_{v}-u_{g}}{\sigma_{v}^{\prime}}\right)^{0.5}\left(\frac{z}{D_{e}}\right)^{-1.25}\right)\right) \quad y / D_{e} \geq 0.01$

$p_{u}=2.4 \sigma^{\prime}{ }_{v} D_{e}\left(\frac{q_{c}}{\sigma^{\prime}{ }_{v}}\right)^{0.67}\left(\frac{z}{D_{e}}\right)^{0.75}$

Equation (5) requires interpolation between equations (5a) and (5b) for $0.0001<y / D_{e}<0.01$. 


\section{Formulation check}

To check the validity of Equation (5), the predictions for $p /\left(\sigma_{v}^{\prime} D\right)$ obtained using this equation for $y / D$ ratios up to 0.1 are compared in Figure 7 with values calculated from the current series of FE analyses (comprising pile diameters of $0.5 \mathrm{~m}$ and $2.0 \mathrm{~m}$ in loose and dense sand with various water table locations) and the analyses reported in Suryasentana \& Lehane (2014a), which involved 10 different sand types and 10 pile diameters. It is evident that a very good fit is obtained to all the data, apart from the predictions from Equation (5) for the smaller diameter pile $(\mathrm{D}=0.5 \mathrm{~m})$, which tend to be lower than the FE calculations for large $p /\left(\sigma^{\prime}{ }_{\nu} D\right)$ ratios. Closer examination of all the analyses indicated that Equation (5) provides conservative estimates of the lateral stiffness at vertical effective stress levels less than about $10 \mathrm{kPa}$.

\section{Verification of proposed p-y formulation}

A standard $p-y$ load transfer program, Oasys ALP (Oasys 2015), was used to conduct laterally loaded pile analyses using $p-y$ curves predicted by Equation (5). This program, which is similar in form to many commercially available laterally loaded pile programs, represents the pile as a series of beam elements and the soil as a series of non-linear, non-interacting springs located between each beam element. The predicted pile responses are compared here against the responses calculated using 3D FE analyses and also against data from an offshore wind farm.

\section{Verification against 3D FE calculations}

Although the finite element (FE) method is generally considered the best means for analysing laterally loaded piles, the high computational resources and modelling complexity required by the FE method limits its widespread adoption by practitioners. One of the main advantages of the $p-y$ method compared to FE method is its ease in providing reasonably accurate predictions very quickly. Comparisons are made in the following between the pile head load-displacement 
response predicted using the $p-y$ approach with Equation (5) and the FE method. The following cases are examined for a $2 \mathrm{~m}$ diameter, $40 \mathrm{~m}$ long pile (as per Case F1 in Table 1):

- Uniform loose sand in dry conditions and with water at $z=0$ and $z=3 \mathrm{~m}(1.5 \mathrm{D})$

- A 3m dense sand layer overlying a deep uniform loose sand layer in dry conditions and with water at $\mathrm{z}=0$ and $\mathrm{z}=3 \mathrm{~m}(1.5 \mathrm{D})$

The CPT $q_{c}$ profiles for each case (allowing for the different assumed locations of the water table) are provided in Figure 8. As for other $q_{c}$ predictions in this paper, these profiles were derived using the spherical cavity expansion procedure described in Suryasentana \& Lehane (2014a) for the $H S$ soil parameters listed in Table 2.

Figure 9 compares the pile head load-displacement predictions obtained using Equation (5) and the $p-y$ method with the FE calculations. It is seen that, despite the considerable added complexity associated with performing 3D FE analyses, Equation (5) leads to predictions that differ by less than $10 \%$ from the FE calculations for the cases analysed. Such small differences are consistent with those obtained in separate analyses (e.g. those analyses reported in Suryasentana \& Lehane 2014b).

Verification against offshore wind farm field study

Hald et al. (2009) reported full scale load measurements on an instrumented wind turbine in the Horns Rev Offshore Wind Farm, which is approximately $30 \mathrm{~km}$ west of Esbjerg in the North Sea. A steel $4 \mathrm{~m}$ diameter monopile was used as the foundation for the instrumented turbine. This pile was driven to an embedment of $21.9 \mathrm{~m}$ (or $31.8 \mathrm{~m}$ below the mean sea level); the pile wall thickness and $E_{p} I_{p}$ varied along the pile as indicated in Table 4. Bending moments obtained at various elevations on the tower indicated that a lateral load of $240 \mathrm{kN}$ and 
corresponding bending moment of $18,700 \mathrm{kNm}$ at ground level occurred during the peak wind speed event.

The measured CPT profile at the site is shown on Fig 14. In keeping with the reported soils data, a unit weight of $20 \mathrm{kN} / \mathrm{m}^{3}$ was adopted for all the sand except in the very loose layer between $14.9 \mathrm{~m}$ and $19.9 \mathrm{~m}$ depth where a value of $17 \mathrm{kN} / \mathrm{m}^{3}$ was assumed. The CPT data combined with these unit weights were sufficient to allow generation of the $p-y$ curves using Equation (4). Subsequent predictions of pile bending moments during the peak wind event (using OASYS ALP) are shown on Figure 10 and are seen to only slightly over-estimate the measured bending moments. Such good agreement is encouraging given the high vertical variability of the in-situ $q_{c}$ values and supports the contention that Equation (4) can be used for the analysis of large diameter offshore piles.

\section{Conclusions}

The paper builds on previous research to develop an updated, numerically derived, CPT based formulation for the estimation of $p-y$ springs for the analysis of laterally loaded piles in sand under static loading. This formulation, which is shown to be applicable to the practical range of flexural rigidities encountered in practice, was modified to allow for higher normalised lateral stiffness of sand in saturated conditions and for the higher resistances shown by square piles. It is shown that 3D FE predictions of pile response are well matched using a standard load transfer program coupled with the proposed $p-y$ formulation. This approach is also shown to provide very good predictions for the bending moments measured on a large diameter offshore monopile. 


\section{References}

API (American Petroleum Institute) (2011). Geotechnical and foundation design considerations, ANSI/API RP 2GEO, 1st edn. Washington DC, USA: API Publishing Services.

Ashour, M. \& Norris, G. (2000). Modeling lateral soil-pile response based on soil-pile interaction. Journal of Geotechnical and Geoenvironmental Engineering 126, No. 5, $420-428$.

DNV (2013). Design of Offshore Wind Turbine Structures (DNV-OS-J101), $1^{\text {st }}$ edn. Oslo, Norway: Det Norske Veritas.

Dobry R., Vicente E., O’Rourke M.J. and Roesset J.M. (1982). Horizontal stiffness and damping of single piles. J. Geotechnical Engineering Div., ASCE, 108(GT\#), 439-459.

Dyson, G. \& Randolph, M. (2001). Monotonic lateral loading of piles in calcareous sand. Journal of Geotechnical and Geoenvironmental Engineering 50, No. 1, 346-352.

Fan, C. \& Long, J. H. (2005). Assessment of existing methods for predicting soil response of laterally loaded piles in sand. Computers and Geotechnics 32, No. 4, 274-289.

Gleser, S.M. (1984). Generalized behavior of laterally loaded vertical piles. In Laterally Loaded Deep Foundations: Analysis and Performance (eds. J. A. Langer, E. T. Mosley, \& C. D. Thompson), pp. 72-96. ASTM.

Hald, T., Mørch, C., Jensen, L., LeBlanc, C. \& Ahle, K. (2009). Revisiting monopile design using p-y curves - Results from full scale measurements on Horns Rev, report to DONG Energy A/S.

Jardine, R. J. (1992). Non-linear stiffness parameters from undrained pressuremeter tests. Can. Geotech. J. 29, No. 3, 436-447.

Li, W., Igoe, D. \& Gavin, K., 2014. Evaluation of CPT based p-y models for laterally loaded piles in sand. Géotechnique Letters, 2, No. 2, 110-117. 
Murchison, J. M. \& O'Neill, M. W. (1983). An evaluation of $p-y$ relationships in sands, report to American Petroleum Institute. Houston, TX, USA: University of Houston.

Novello, E. A. (1999). From static to cyclic p-y data in calcareous sediments. In Engineering for calcareous sediments (ed. K. Al-Shafei), vol. 1, pp. 17-24. Rotterdam, the Netherlands: Balkema.

Oasys (2015). Alp software manual. www.oasys-software.com, Oasys, London, UK.

Poulos H.G. \& Hull T. (1989). The role of analytical geomechanics in foundation engineering. In Foundation Engineering: Current Principles and Practices, pp. 1578-1606. NewYork: ASCE.

Reese, L. C. \& Van Impe, W. F. (2001). Single Piles and Pile Group under Lateral Loading, Rotterdam, the Netherlands: Balkema.

Schanz, T., Vermeer, P. A. \& Bonnier, P. G. (1999). The hardening soil model: formulation and verification. In Beyond 2000 in computational geotechnics: ten years of Plaxis International (ed. R. B. J. Brinkgreve), pp. 281-296. Rotterdam, the Netherlands: Balkema.

Suryasentana, S. K. \& Lehane, B. M. (2014a). Numerical derivation of CPT-based p-y curves for piles in sand. Géotechnique 64, No. 3, 186-194.

Suryasentana, S. K. \& Lehane, B. M. (2014b). Verification of numerically derived CPT based p-y curves for piles in sand. Proceedings of 3rd International Symposium on Cone Penetration Testing, Las Vegas, NV, paper 3-29.

Tatsuoka, F., Jardine, R. J., Lo Presti, D., Di Benedetto, H. \& Kodaka, T. (1997). Characterising the pre-failure deformation properties of geomaterials. Proceedings of the 14th international conference on soil mechanics and foundation engineering. Hamburg, Germany, vol. 4, pp. 2129-2164. 


\section{Notation}

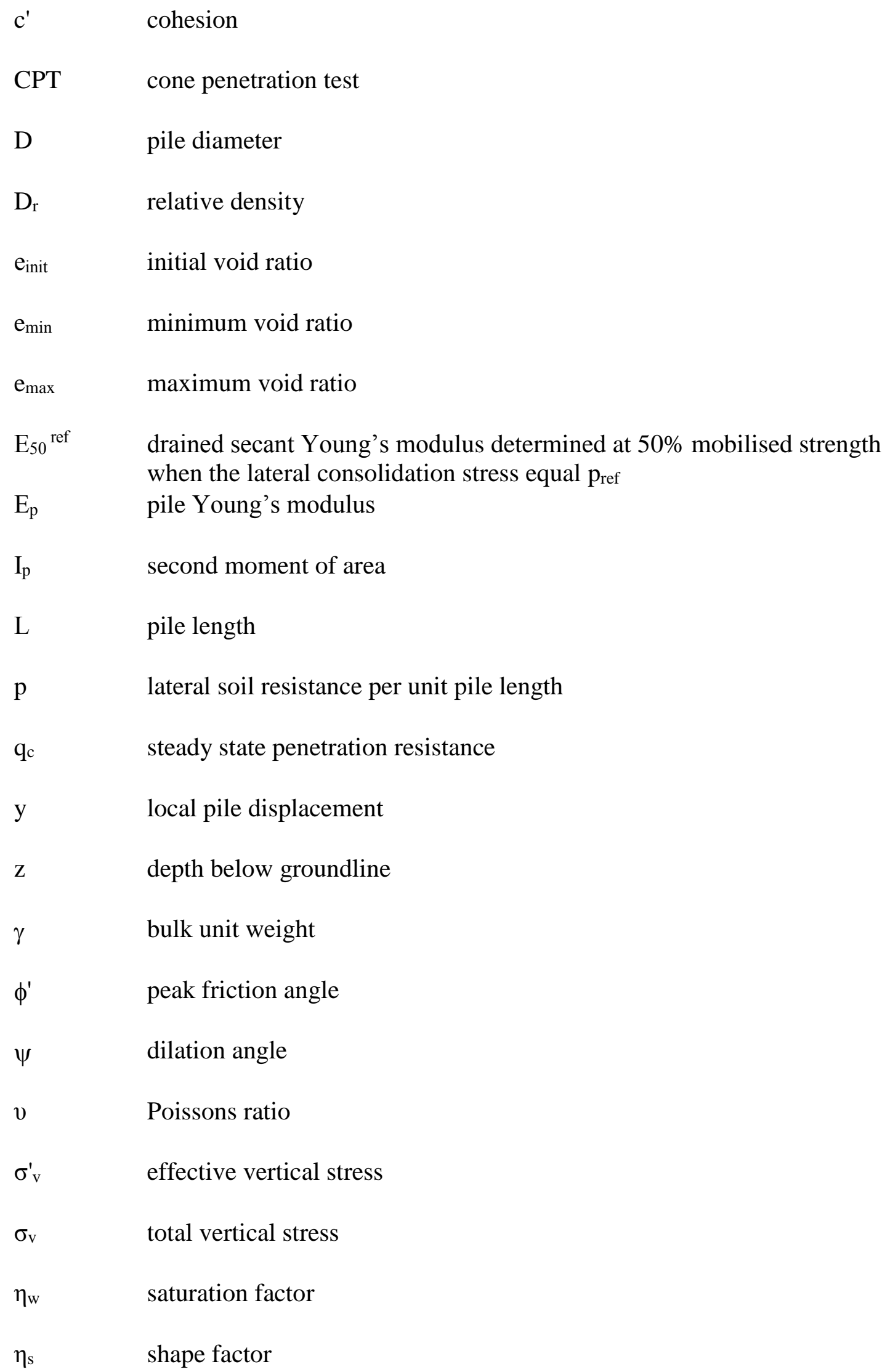




\begin{tabular}{lllll}
\hline & $\begin{array}{l}\text { Flexible Pile } \\
(\text { F1 })\end{array}$ & $\begin{array}{l}\text { Flexible Pile } \\
(\text { F2) }\end{array}$ & $\begin{array}{l}\text { Flexible Pile } \\
(\mathbf{F 3 )}\end{array}$ & Rigid Pile \\
\hline Cross-section & Circular & Circular & Circular & Circular \\
Material type & Linear Elastic & Linear Elastic & Linear Elastic & Linear Elastic \\
Drainage type & Non-porous & Non-porous & Non-porous & Non-porous \\
$\mathrm{E}_{\mathrm{p}}(\mathrm{kPa})$ & $30 \times 10^{6}$ & $30 \times 10^{5}$ & $30 \times 10^{7}$ & $200 \times 10^{6}$ \\
$\gamma_{\text {pile }}\left(\mathrm{kN} / \mathrm{m}^{3}\right)$ & 24 & 24 & 24 & 77 \\
$v$ & 0.2 & 0.2 & 0.2 & 0.2 \\
$\mathrm{D}(\mathrm{m})$ & 2 and 0.5 & 2 and 0.5 & 2 and 0.5 & 2 and 0.5 \\
L $(\mathrm{m})$ & 40 and 10 & 40 and 10 & 40 and 10 & 10 and 2.5 \\
\hline
\end{tabular}

Table 1: Pile properties used for Case (a), (b) and (d) 


\begin{tabular}{lll}
\hline & Loose Sand & Dense Sand \\
\hline $\mathrm{e}_{\text {init }}$ & 0.7 & 0.55 \\
$\mathrm{e}_{\text {max }}$ & 0.78 & 0.78 \\
$\mathrm{e}_{\text {min }}$ & 0.49 & 0.49 \\
$\mathrm{D}_{\mathrm{r}}$ & 0.28 & 0.79 \\
$\mathrm{~K}_{\mathrm{o}}$ & 0.45 & 0.45 \\
$\gamma_{\text {unsaturated }}\left(\mathrm{kN} / \mathrm{m}^{3}\right)$ & 18 & 18 \\
$\gamma_{\text {saturated }}\left(\mathrm{kN} / \mathrm{m}^{3}\right)$ & 21 & 21 \\
$v$ & 0.2 & 0.2 \\
$\mathrm{E}_{50}{ }^{\text {ref }}(\mathrm{kPa})$ & 20000 & 60000 \\
$\mathrm{E}_{\text {oed }}{ }^{\text {ref }}(\mathrm{kPa})$ & 20000 & 60000 \\
$\mathrm{E}_{\text {ur }}{ }^{\text {ref }}(\mathrm{kPa})$ & 60000 & 180000 \\
$\mathrm{c}(\mathrm{kPa})$ & 0 & 0 \\
$\phi($ degrees $)$ & 36.1 & 45.2 \\
$\psi($ degrees $)$ & 5 & 12 \\
\hline
\end{tabular}

Table 2: Soil properties used for Cases (a) to Case (d) 


\begin{tabular}{lllll}
\hline & $\begin{array}{l}\text { Circular Pile } \\
(\mathbf{F 1})\end{array}$ & $\begin{array}{l}\text { Square Pile } \\
(\mathbf{S 1})\end{array}$ & $\begin{array}{l}\text { Square Pile } \\
(\mathbf{S 2})\end{array}$ & $\begin{array}{l}\text { Square Pile } \\
(\mathbf{S 3})\end{array}$ \\
\hline Cross-section & Circular & Square & Square & Square \\
Material type & Linear Elastic & Linear Elastic & Linear Elastic & Linear Elastic \\
Drainage type & Non-porous & Non-porous & Non-porous & Non-porous \\
E $_{\mathrm{p}}(\mathrm{kPa})$ & $30 \times 10^{6}$ & $17.7 \times 10^{6}$ & $30 \times 10^{6}$ & $46.5 \times 10^{6}$ \\
$\gamma_{\text {pile }}\left(\mathrm{kN} / \mathrm{m}^{3}\right)$ & 24 & 24 & 24 & 24 \\
$v$ & 0.2 & 0.2 & 0.2 & 0.2 \\
Width $(\mathrm{m})$ & 2 and 0.5 & 2 and 0.5 & 1.75 and 0.438 & 1.57 and 0.393 \\
L $(\mathrm{m})$ & 40 and 10 & 40 and 10 & 40 and 10 & 40 and 10 \\
\hline
\end{tabular}

Table 3: Pile properties used to compare square and circular piles 


\begin{tabular}{|c|c|c|}
\hline Depth below pile head (m) & Wall thickness (mm) & $E_{p} I_{p}\left(\mathrm{x10}^{8} \mathrm{kNm}^{2}\right)$ \\
\hline $0-11.8$ & 50 & 2.54 \\
\hline $11.8-19.6$ & 52 & 2.64 \\
\hline $19.6-23.6$ & 50 & 2.54 \\
\hline $23.6-27.6$ & 40 & 2.05 \\
\hline $27.6-31.6$ & 40 & 2.05 \\
\hline
\end{tabular}

Table 4: Properties of steel monopile foundation for Horns Rev wind turbine, assuming $\mathrm{E}_{\mathrm{p}}=210 \mathrm{GPa}$ (Hald et al. 2009) 

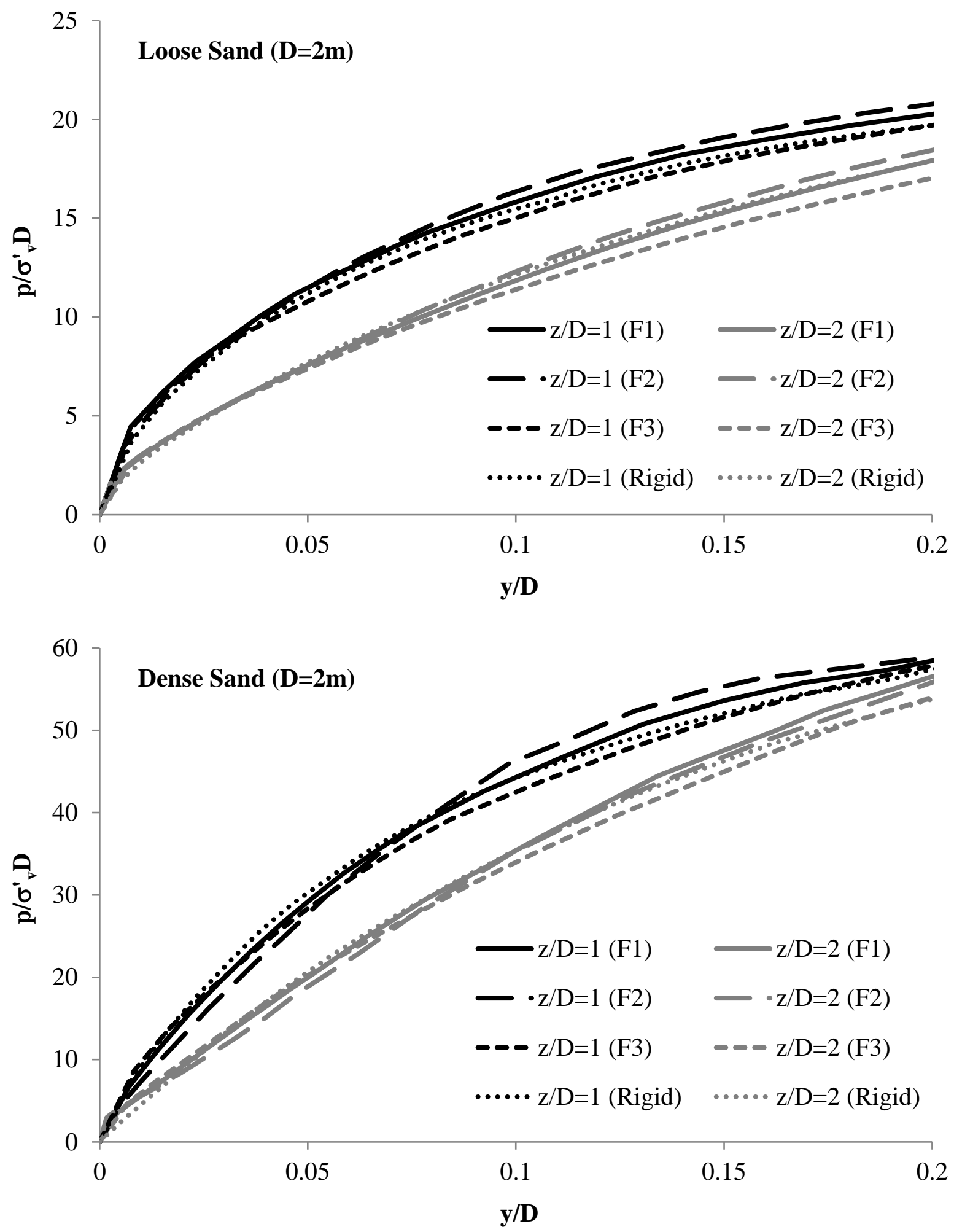

Figure 1: Comparison of $p-y$ curves of flexible piles with varying $E_{p} I_{p}$ 

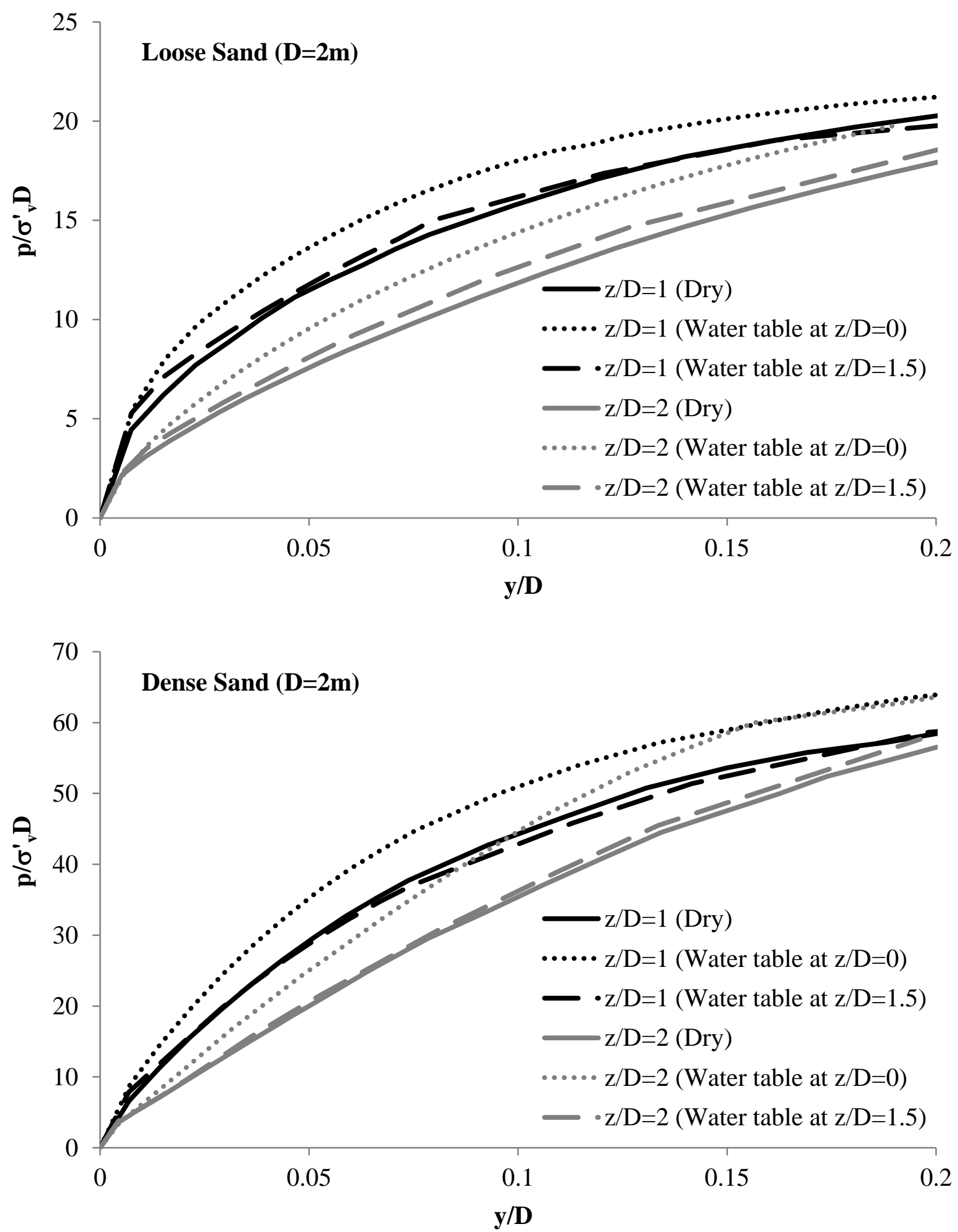

Figure 2: Comparison of p-y curves of a flexible pile (F1) obtained under various saturation conditions 

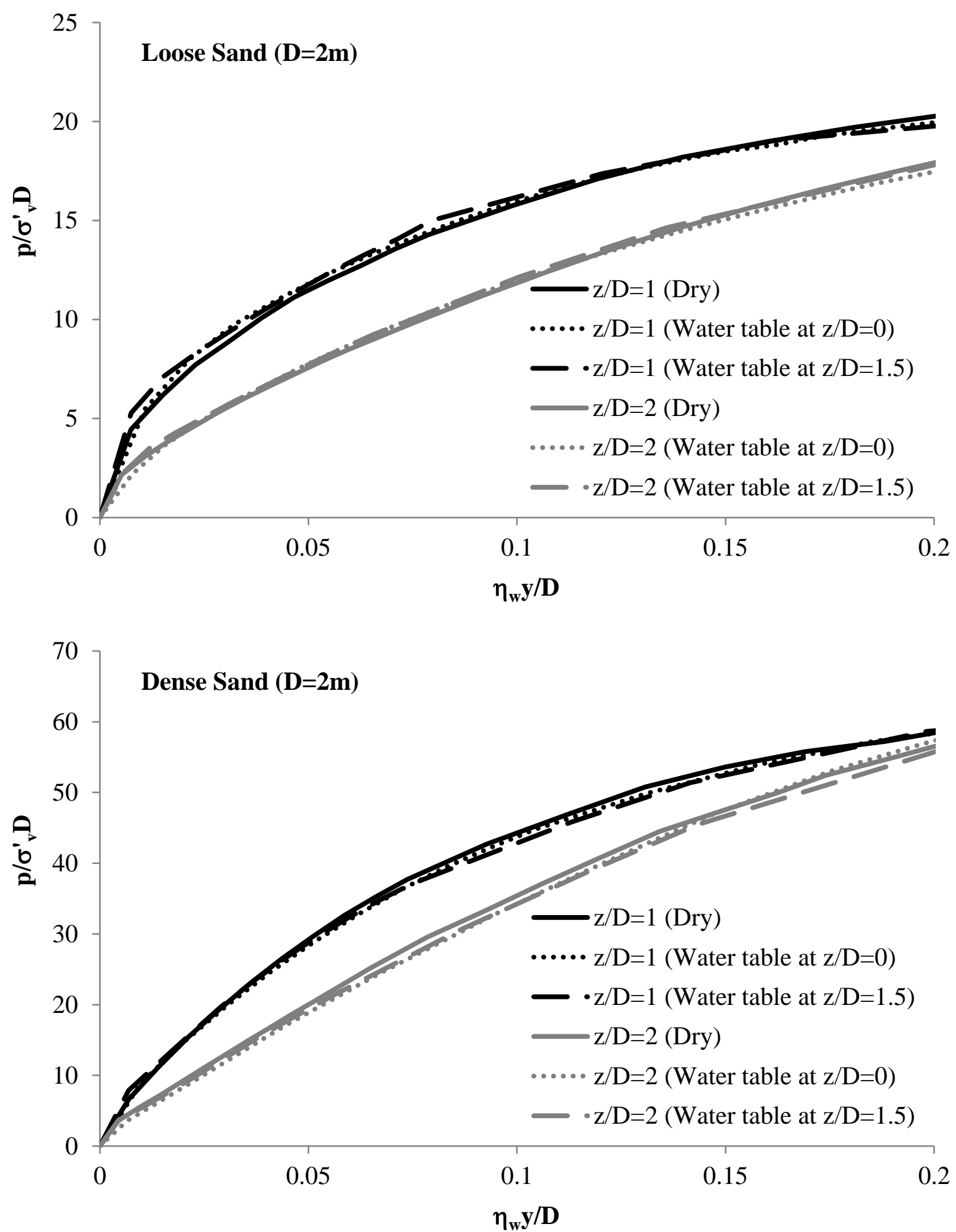

Figure 3: Incorporation of saturation factor to $p-y$ curves shown in Figure 2 

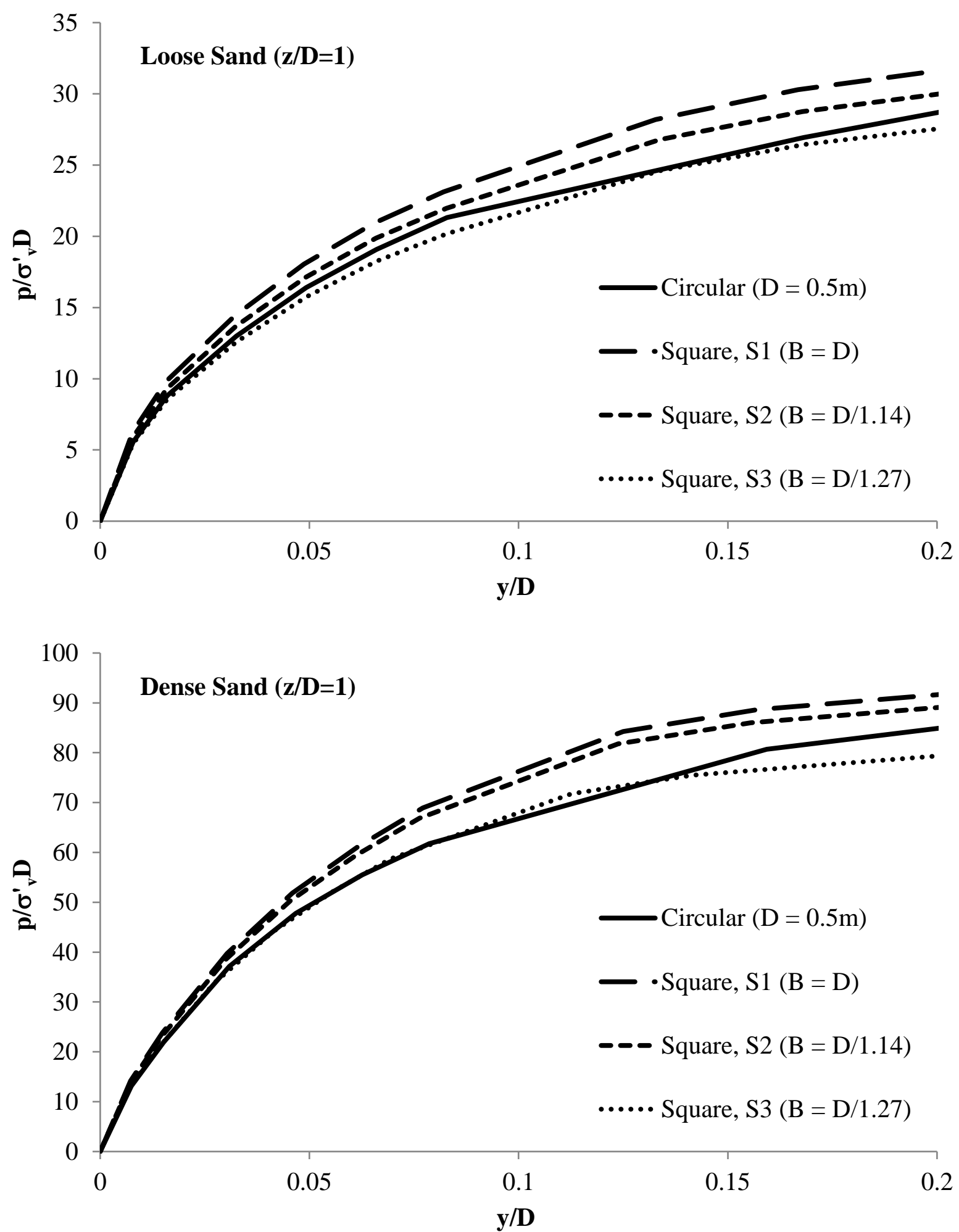

Figure 4: Comparison of $p-y$ curves of square and circular piles (only the curves at $\mathrm{z} / \mathrm{D}=1$ are shown for clarity purposes) 

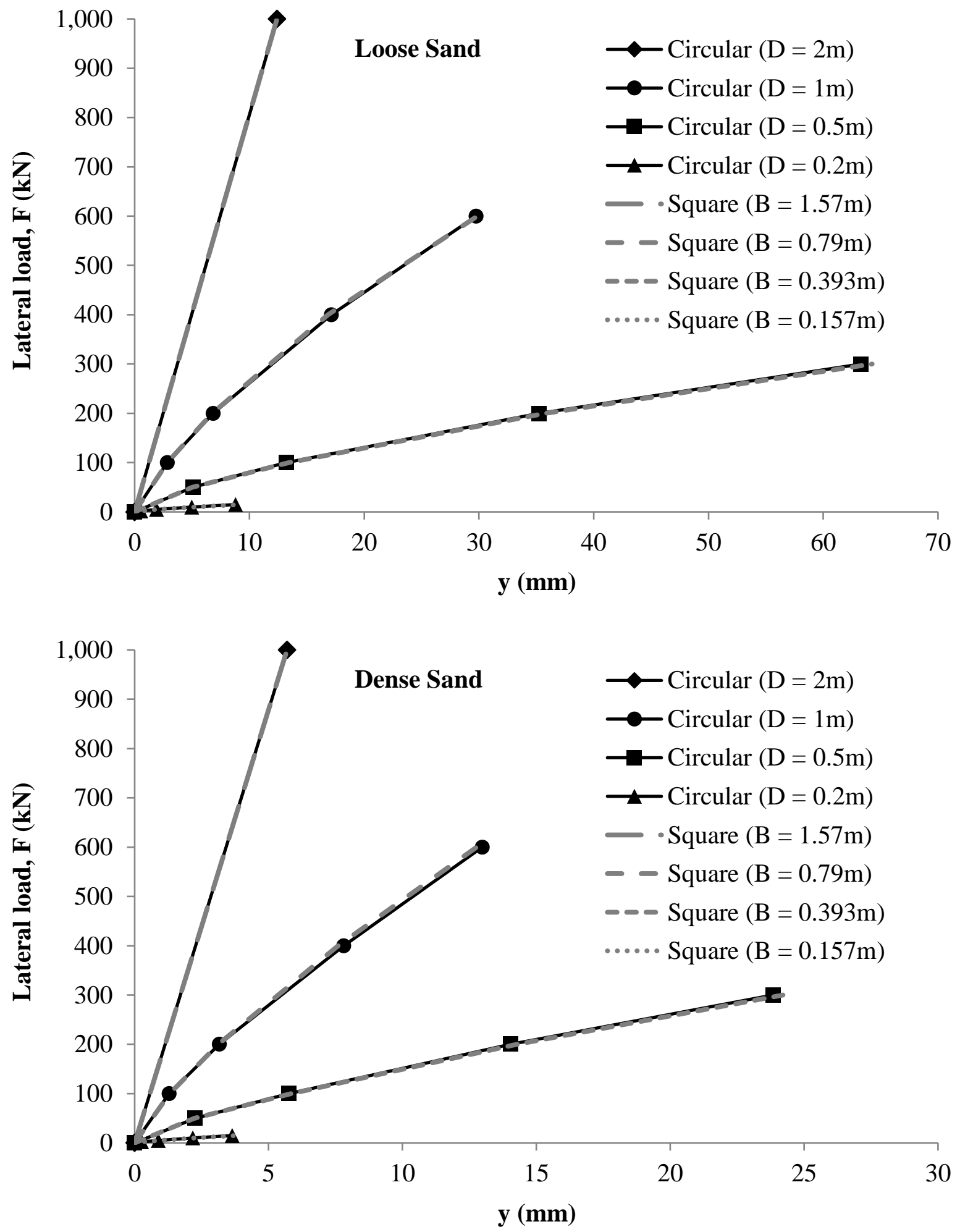

Figure 5: Predictions for pile head load displacement for circular piles of different diameters and their corresponding square piles with $\mathrm{B}=\mathrm{D} / 1.27$. 

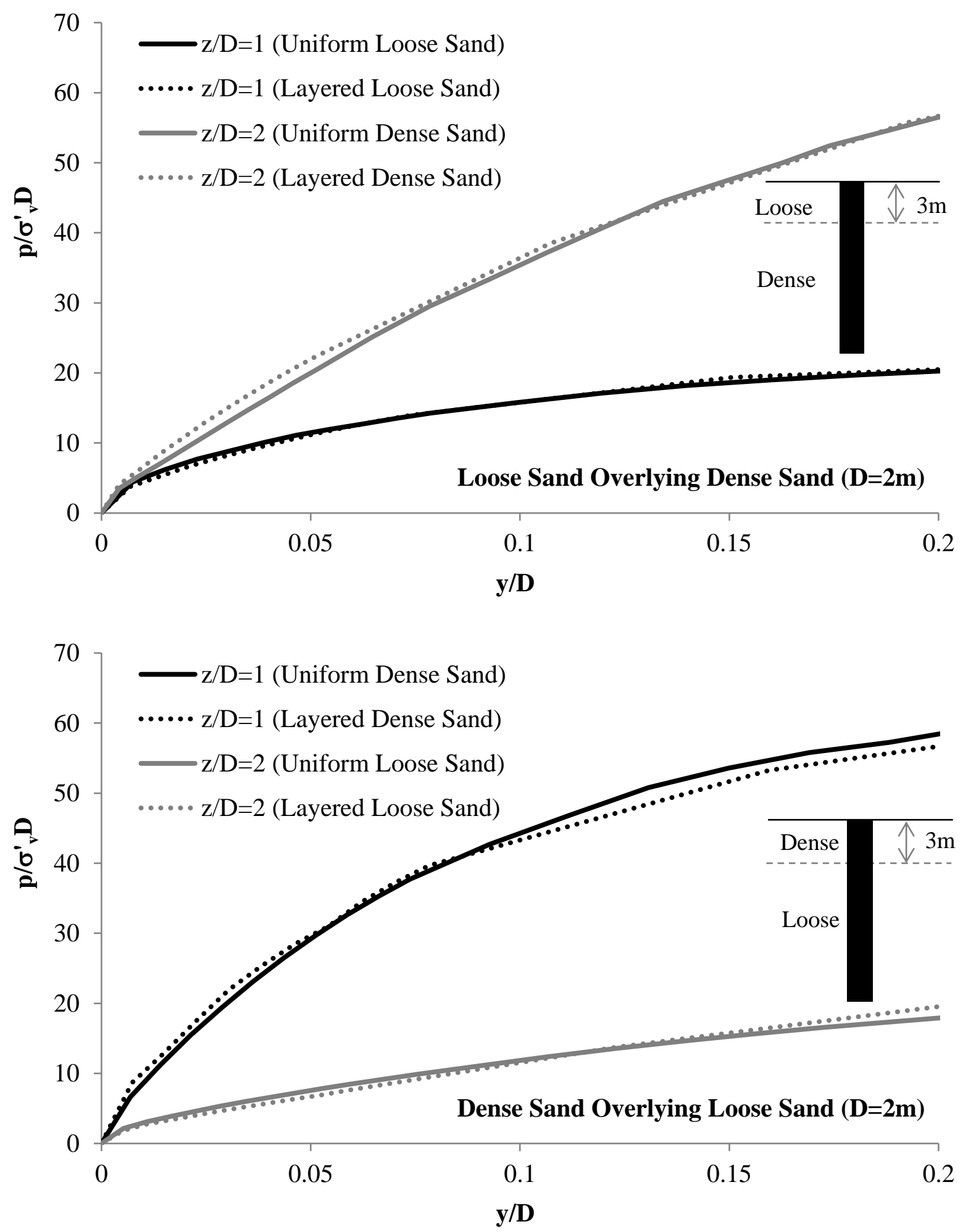

Figure 6: Comparison of p-y curves obtained from a two-layer soil configuration against that obtained from a homogeneous soil configuration 


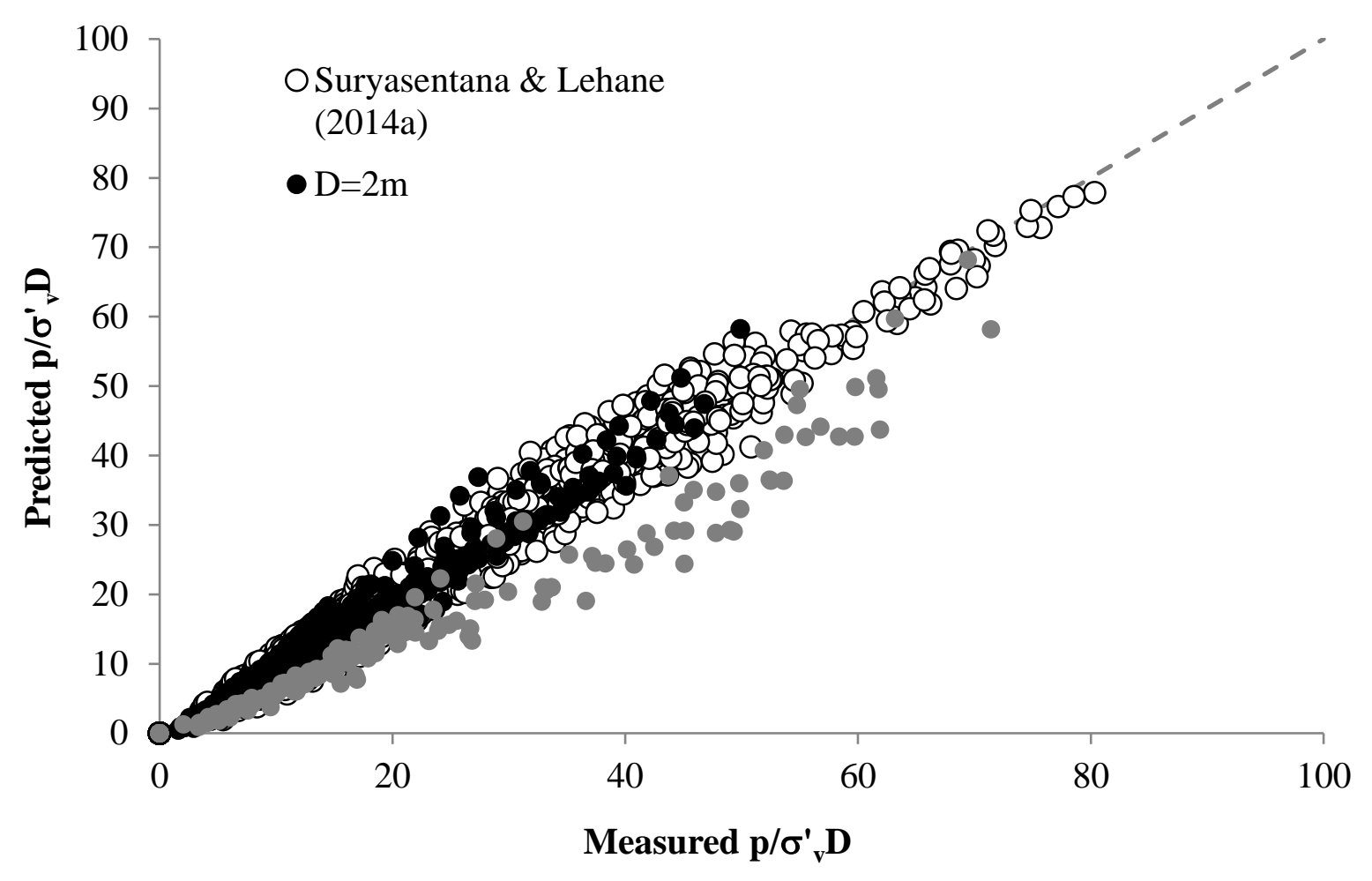

Figure 7: Comparison of $p / \sigma_{\mathrm{v}} \mathrm{D}$ predicted by Equation 5 vs measured $p / \sigma_{\mathrm{v}}{ }_{\mathrm{v}} \mathrm{D}$. 

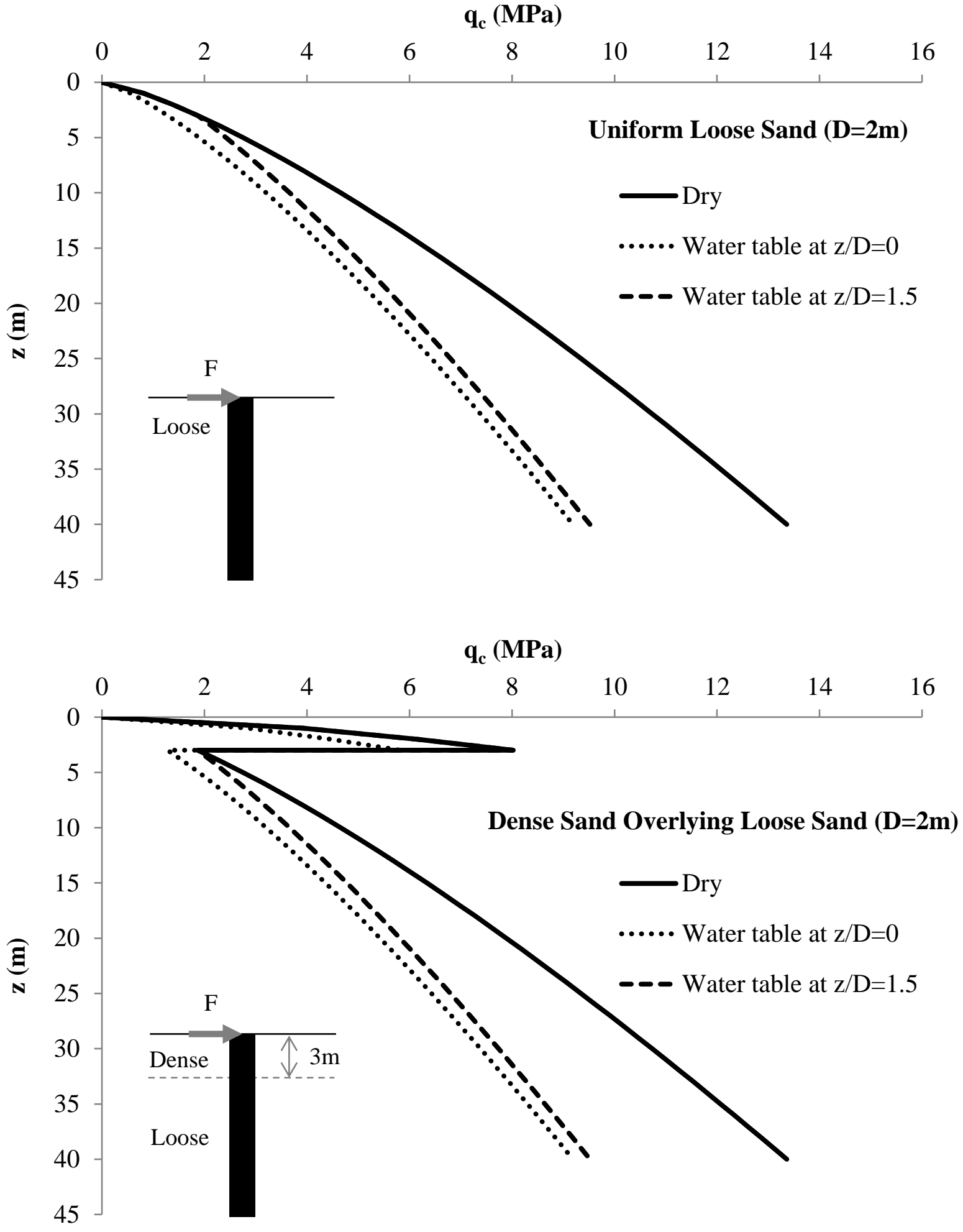

Figure 8: Predicted CPT profiles of numerical test cases using the cavity expansion method 

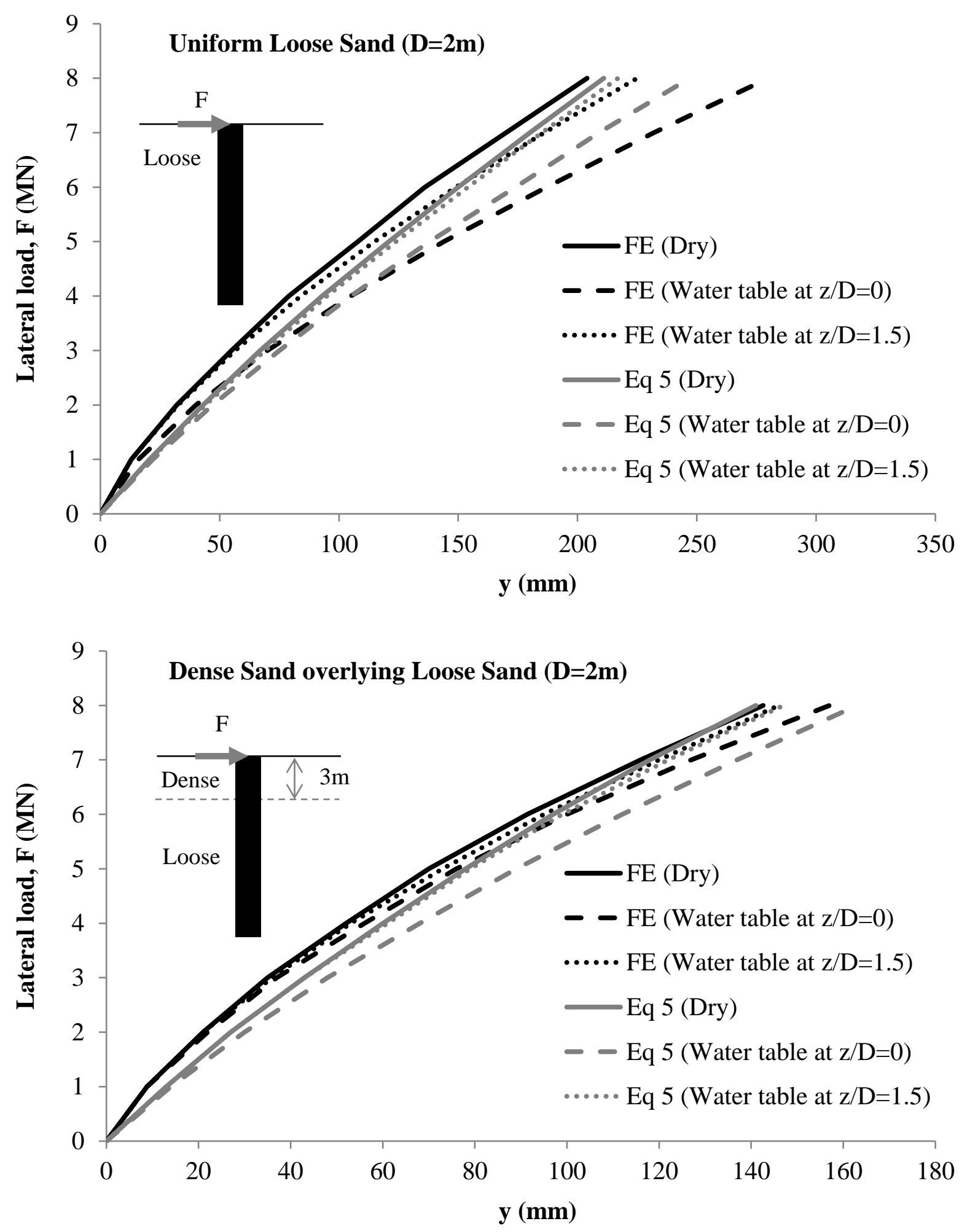

Figure 9: Comparison of pile head load-displacement predictions using Equation 5 with the FE method. 


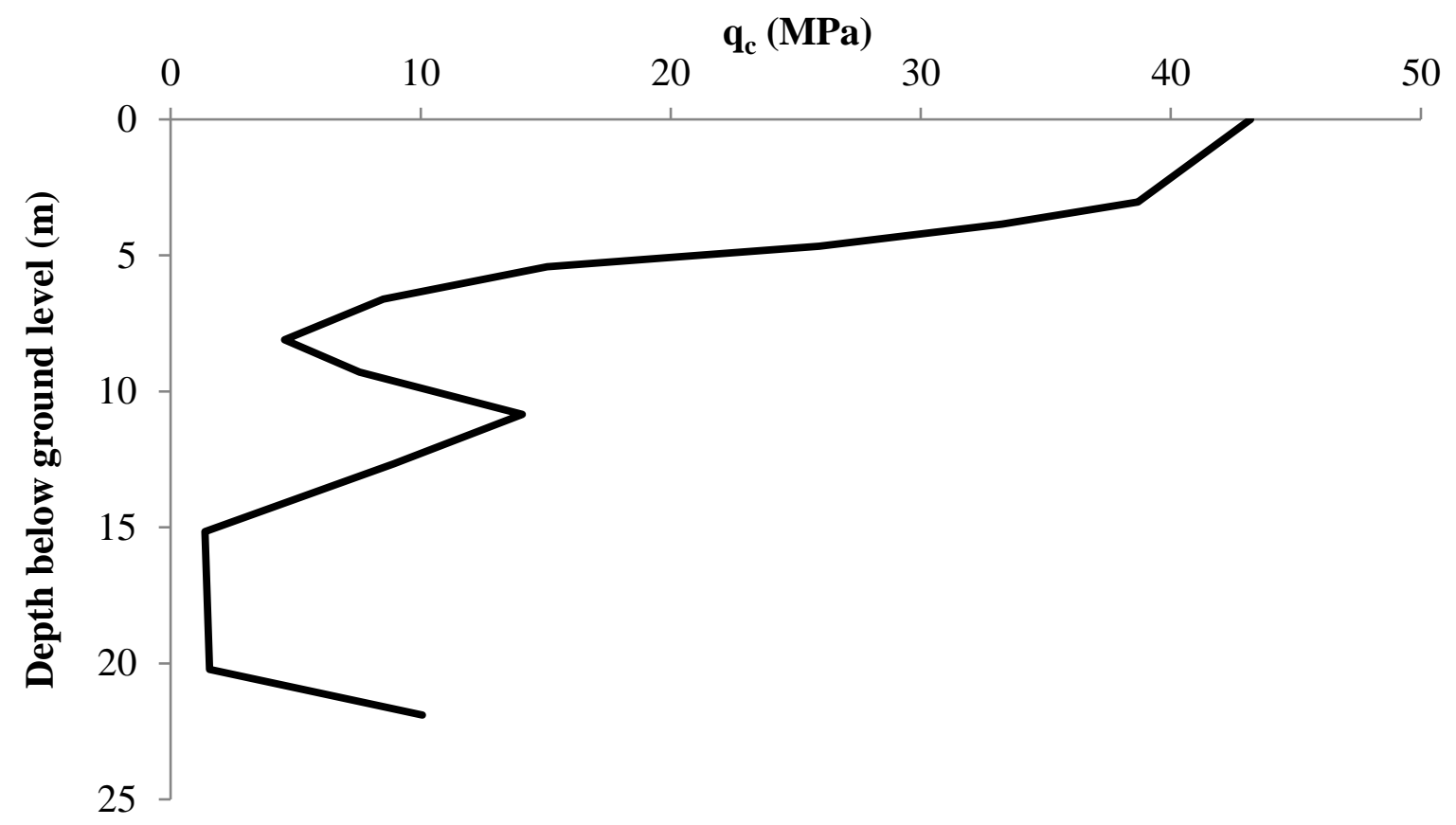

Bending Moment (MNm)

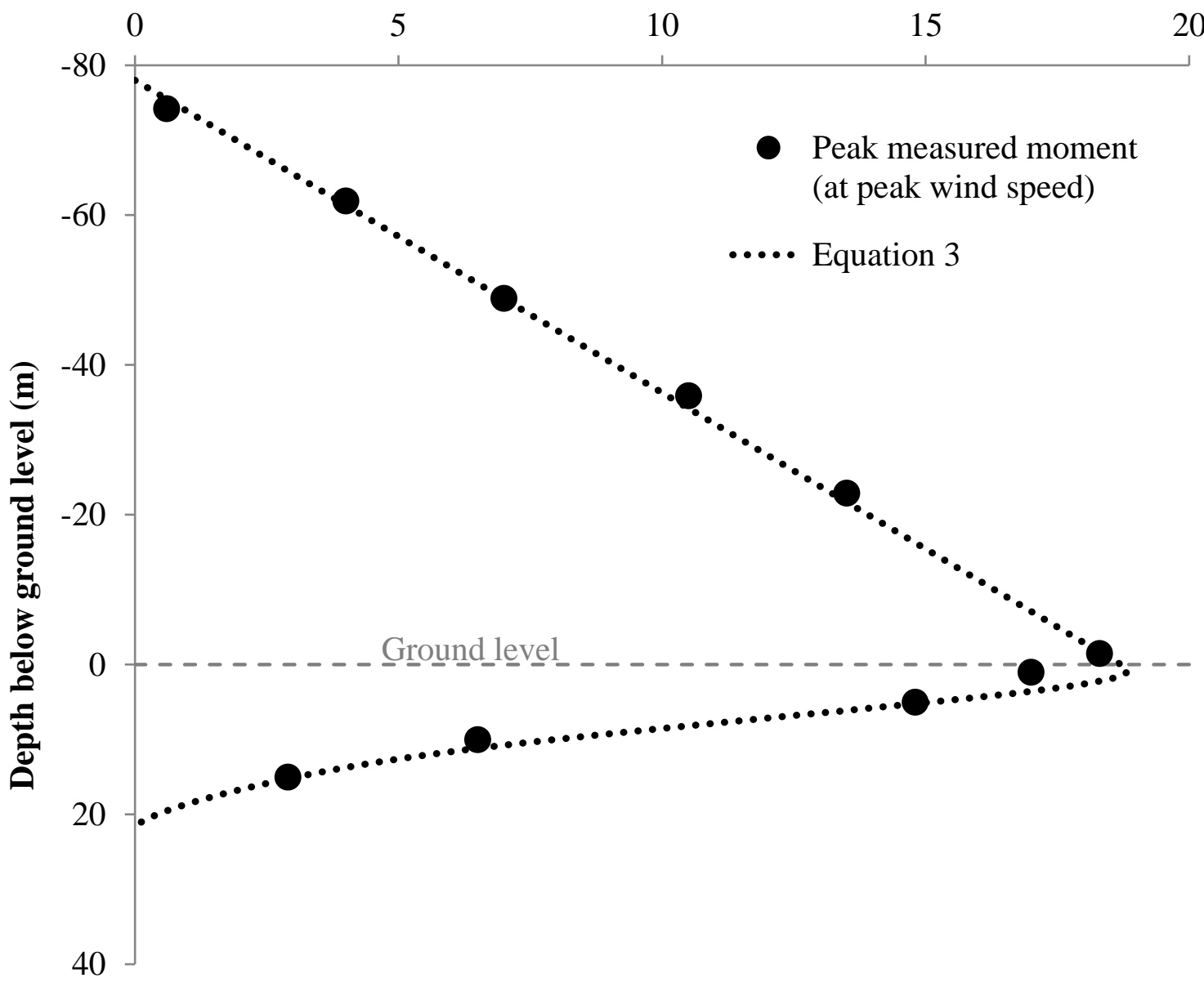

Figure 10: Measured CPT profile at the Horns Rev wind turbine site (Hald et al. 2009) and the comparison of measured peak bending moments and bending moments predicted using Equation 5. 